\title{
De inquilinos a propietarios. Derecho y política en el Programa de Renovación Habitacional Popular
}

\author{
Antonio Azuela de la Cueva*
}

EI presente trabajo ofrece un anáiisis del papel de las instituciones jurídicas en la transformación de las relaciones de propiedad en el centro de ia ciudad de México a partir del sismo de 1985, es decir, en ei cambio de estatus de inquilinos a propietarios que ha traído consigo el Programa de Renovación Habitacional Popular. Se examinan, en primer lugar, los antecedentes y las implicaciones jurídicas y politicas del decreto expropiatorio de más de cuatro mil predios con que se fijó el alcance del programa. En segundo lugar, se describe el Convenio de Concertación Democrática para la Reconstrucción de Vivienda del Programa de Renovación Habitacional, destacando el contraste entre su importancia política y su invalidez jurídica. Asimismo, se examina el régimen de propiedad en condominio "de carácter vecinal" contenido en el nuevo capítulo de la ley de la materia, destacando los debates ideológicos que tuvieron lugar en el proceso de su discusión en la cámara de diputados. Finalmente, se incluye una breve referencia a los juicios de amparo promovidos por numerosos propietarios afectados por la expropiación y se señala su importancia como obstáculo a la ejecución del Programa de Renovación Habitacional.

\section{Introducción}

Los sismos de septiembre de 1985 dejaron en la ciudad de México una secuela de devastación que alteró en diversas direcciones las tendencias que se observaban en su área central los últimos años. Dejando a un lado la pérdida de vidas humanas, los daños producidos en más de cinco mil edificaciones ${ }^{1}$ significaron, en primer lugar, una drástica reducción del equipamiento social acumulado durante décadas de inversión pública en salud y educación. Asimismo, se aceleró el deterioro del inventario habitacional que han venido sufriendo los habitantes de esa área, y al mismo tiempo se interrumpió bruscamente el proceso de terciarización del centro con la destrucción de centenares de edificios de oficinas. ${ }^{2}$

A partir de entonces, el centro de la capital del país ha vivido procesos sociales inéditos en su historia. Sin contar la movilización política de los damnificados, y en gran parte como resultado de ésta, el más impor-

* Profesor-investigador visitante del Centro de Estudios Demográficos y de Desarrollo Urbano de El Colegio de México.

${ }^{1}$ Para un análisis de los daños producidos por los sismos, véase la colaboración de Priscilla Connolly en este mismo volumen.

${ }^{2}$ Fueron dañados 196 edificios públicos, perdiéndose más de 1600000 metros cuadrados de oficinas donde laboraban más de 145000 servidores públicos (CME, 1985: 8). 
tante de estos procesos es la transformación de la propiedad de las viviendas incorporadas al Programa de Renovación Habitacional Popular (en adelante PRHP) que se generó a partir de la expropiación masiva de predios decretada por el Presidente de la República.

La importancia de esta transformación radica no únicamente en el cambio de la situación legal de los habitantes de los predios expropiados, quienes se convierten en propietarios - bajo el régimen de condominio- de las viviendas que antes ocupaban como arrendatarios. Esta definición legal adquiere un enorme significado económico y social por la acción propiamente habitacional del gobierno. Si el PRHP cumple sus metas, habrá 44000 familias que podrán - cuando liquiden sus créditos- disponer libremente de viviendas cuyas condiciones físicas son muy superiores al promedio en el área central. Así, además del efecto demostración que pueda producir la existencia de esas viviendas, éstas podrán circular legalmente como mercancías, en un mercado en el que estarán del lado de la oferta quienes ayer estaban en el de la demanda.

El objeto de este trabajo es analizar las condiciones jurídico-políticas que han operado en este proceso de transformación de la propiedad, a fin de aportar elementos que permitan comprender la importancia del sistema jurídico como elemento condicionante de la acción gubernamental y no únicamente como mero "instrumento" que el poder público utiliza a placer. ${ }^{3}$

\section{La expropiación. Crónica de un acto fallido}

En medio de la confusión y el caos que reinaron las semanas siguientes a los sismos, y de la incertidumbre que aún prevalece en torno al futuro del centro de la ciudad (agravada por la profundización de la crisis económica) se produjo un evento que transformó el horizonte político de esa coyuntura y abrió un nuevo proceso social en la ciudad de México: la expropiación de más de 5000 predios dedicados a uso habitacional y la creación de un organismo responsable de desarrollar un programa de mejoramiento de vivienda en favor de la población damnificada. En las siguientes líneas se ofrece un breve análisis y algunas reflexiones en torno al significado de esta medida y de las perspectivas que con ella se presentan.

Antes de abordar nuestro objeto de estudio, es preciso señalar que una expropiación como ésta (que desplaza al propietario del suelo urbano para distribuir éste entre los ocupantes) tiene numerosos e importantes antecedentes en la política urbana de esta ciudad, a pesar de que en esta ocasión

${ }^{3}$ La concepción de lo jurídico como instrumento del poder público aparece tanto en el discurso de la planeación como en el de la mayor parte de los análisis sociológicos de las políticas urbanas. Véase por ejemplo Lojkine (1979). 
se anunció como una acción "sin precedentes".

A fines de los años treinta y durante la primera mitad de los cuarenta, los conflictos sociales surgidos entre fraccionadores y colonos en la formación de barrios populares en la periferia de la ciudad eran resueltos muchas veces mediante la expropiación de los predios y su distribución a precios bajos a los colonos. Se hacía imposible llevar a la práctica los esquemas jurídicos vigentes (propiedad privada con un mínimo control estatal a la urbanización) ante la aparición de nuevos agentes políticos en una urbanización de masas que rebasaba la lógica del mercado. Así, la expropiación se convertía en un medio de intervención estatal de fuerte tinte paternalista, frecuentemente demandada por las organizaciones de colonos. Solamente en el periodo 1940-1946 las expropiaciones para dotar a nuevos ocupantes o regularizar la posesión de los existentes alcanzó 72 colonias populares con un total de 28000 lotes unifamiliares. ${ }^{4}$ Aunque no existen investigaciones al respecto, no es demasiado riesgoso decir que estas expropiaciones contribuyeron a mantener el consenso social entre las masas urbanas que ha sido clave para la estabilidad política de la ciudad de México.

Ahora bien, las condiciones políticas en las que se realizó la expropiación que nos ocupa tiene rasgos muy particulares; quizá el más importante es que la movilización social que se produjo después del sismo llegó a articular la atención de la emergencia con la organización de la protesta.

Efectivamente, cuando comenzaba a superarse el caos que prevaleció en la respuesta gubernamental durante los días siguientes al sismo, en muchos barrios centrales las organizaciones existentes de vecinos habían demostrado su capacidad para atender algunos aspectos de la emergencia: no sólo en la canalización del auxilio que proporcionaban los propios habitantes de los barrios, con lo cual las organizaciones crecían como nunca antes, sino también en el manejo de ayuda externa. En la colonia Guerrero, por ejemplo, fue la Unión de Vecinos en quien la UNICEF depositó la responsabilidad de llevar a cabo la campaña de vacunación infantil.

Uno de los problemas que enfrentó la población de la zona de desastre fue la presión de numerosos casatenientes que, bajo pretexto de los daños ocasionados por el sismo, o aprovechando la confusión reinante, trataron de desalojar a sus inquilinos llegando incluso a iniciar la demolición de viviendas que no habían sufrido daños. También en la atención de esta emergencia fueron las asociaciones de vecinos quienes organizaron la defensa social del espacio y denunciaron el problema.

En algunas zonas, las organizaciones habían ganado terreno a las autoridades locales en la propia gestión de la ciudad, hecho insólito en el con-

${ }^{4}$ Se trata sin duda de un periodo poco estudiado en las políticas públicas sobre las colonias populares. Existe información al respecto en el número 10 de la revista $A$ de la División de Ciencias Sociales de la UAM-Azcapotzalco, así como en DDF (1946: cap. III, 23-24). 
texto del extremo autoritarismo del sistema político de la capital de la República, en el que casi no existe siquiera la democraçia formal.

La incapacidad de las autoridades locales para movilizar eficientemente los recursos disponibles y, sobre todo, para canalizar la ayuda espontánea de la propia sociedad, les acarreó un desprestigio que no pudo ser disimulado. Momentáneamente perturbado el control político sobre los medios de comunicación de masas, éstos dejaron ver como nunca antes el descontento social prevaleciente.

Así, cuando las organizaciones comenzaron a conducir la protesta política, no sólo representaban una inconformidad social sin precedentes -150 000 damnificados (Cepal, 1985: 11)—, sino también el trastocamiento del sistema político local. Por primera vez en su gestión, el Presidente de la Repúblca recibía personalmente a representantes de vecinos, que habían rebasado los marcos de las autoridades locales y que, además, estaban fuera del control del partido oficial.

Fue el 2 de octubre cuando, después de una marcha a la residencia presidencial, los representantes de las organizaciones de las colonias Doctores, Roma, Morelos, Guerrero, Tepito y del conjunto habitacional Tlatelolco, entregaron un pliego petitorio al Presidente de la República, en el cual se incluía, entre otras demandas, la de expropiar edificios y vecindades para impedir el desalojo de los inquilinos por parte de los caseros. Siguiendo los cánones de la política mexicana, no se hizo público que se trataba de una posibilidad que se estaba estudiando.

A pesar de las reiteradas promesas gubernamentales de atender las demandas de los damnificados, la movilización de éstos seguía adelante mientras las acciones de las diversas entidades y dependencias públicas seguían siendo aisladas y profundamente desorganizadas.

En este contexto, el 11 de octubre el jefe del Departamento del Distrito Federal (DDF) anunció la decisión presidencial de expropiar más de cinco mil predios ${ }^{5}$ en las zonas afectadas a fin de iniciar un programa de reconstrucción de viviendas que sería realizado por un organismo creado ad hoc. Revisemos los elementos básicos de este decreto.

El decreto invoca como fundamento seis diferentes leyes que en las Ĺltimas décadas han engrosado el arsenal jurídico disponible para la intervención estatal en los procesos urbanos; intervención que en la práctica rara vez tiene el alcance previsto en la ley y que parecería reservada sólo para las grandes ocasiones. Las causas de utilidad pública que, el estar previstas en dichas leyes, fundamentan esta expropiación, son las siguientes: a) "La satisfacción de necesidades colectivas en caso de. . . trastornos interiores"; b) el "mejoramiento de los centros de población"; c) "el

${ }^{5}$ Inexplicablemente, el regente dijo ante la prensa que se trataba de "más de siete mil", error que no sólo los propios medios de comunicación difundieron, sino que aún repiten muchos autores. 
establecimiento o conservación de un servicio público", y d) "las medidas necesarias para evitar. . . los daños que la propiedad pueda sufrir en perjuicio de la colectividad"' (Ley de Expropiación, artículo 10.).

De acuerdo con el propio decreto, los inmuebles expropiados se destinarían a la realización de "acciones tendientes a la satisfacción de necesidades colectivas de vivienda, en favor de las personas afectadas por los sismos. . . y de regeneración y mejoramiento urbano". Además, se previó enajenar las viviendas que se construyan, "a título oneroso" a quienes ahí habitaban, que tendrán derecho de preferencia para adquirirlas. En otras palabras, se trata de convertir a los antiguos inquilinos en propietarios de las viviendas nuevas o reparadas. Con ello, el gobierno asume el compromiso de evitar un proceso de expulsión de población afectada hacia la periferia de la ciudad, cuyo "arraigo" e "identificación" con el centro se reconocen expresamente en el decreto. Sin embargo, se trata más de un compromiso político que de una obligación propiamente jurídica. Paradójicamente, son los propietarios de los predios expropiados quienes pueden exigir la reversión de los mismos (esto es, su devolución) si en un plazo de cinco años no son destinados al fin previsto por el decreto.

Finalmente en lo que se refiere a la indemnización a los propietarios, el decreto establece que será cubierta en un plazo que no excederá de 10 años, que es el máximo permitido por la ley.

El anuncio del decreto provocó las más diversas reacciones. Por parte de los propietarios afectados no se produjo una reacción con trascendencia política significativa, ya que carecen de un espacio político relevante, lo cual deriva sin duda de su escasa importancia en relación con otros sectores económicos. Sobra decir que las organizaciones incorporadas al partido oficial manifestaron de inmediato su apoyo y no dudaron en comparar la medida con las nacionalizaciones de la industria petrolera (1938) y de la banca (1982). Las organizaciones de vecinos expresaron también su adhesión, solicitando al mismo tiempo que se ampliara la cobertura del decreto y se definieran las bases del programa de reconstrucción habitacional (Unomásuno, 14 de octubre de 1985).

En el otro extremo, un sector de las agrupaciones de pequeños y medianos empresarios expresaban su rechazo a la medida, con el apoyo de algunos medios informativos. Pero este rechazo no debe sorprender al porvenir de sectores que han definido a ultranza la propiedad privada. Lo que es interesante destacar es el apoyo que manifestaron a la expropiación las cúpulas de las agrupaciones de grandes empresas. Notablemente, la empresa que monopoliza la televisión privada expresó por ese medio su adhesión. Más aún, su entonces vicepresidente, Miguel Alemán Velasco dijo en una ceremonio pública: "el día de mañana esta acción será destacada como un gran hecho político de la historia de México" (CNR, 1985: 49).

En otras palabras, se puso en funcionamiento una de las más podero- 
sas alianzas entre la clase política y la burguesía nacional. Y aunque esto ocurría precisamente en el terreno de la comunicación social, no fue suficiente para convencer a la (no tan) pequeña burguesía y la clase media alta de las bondades de la medida. En estos sectores, crecientemente inconformes con los últimos gobiernos por su incapacidad de satisfacer sus expectativas de consumo en la actual crisis económica, la expropiación fue vista como una vuelta al "populismo" que tanto se reprocha a regímenes anteriores y que parecía haberse erradicado en la presente administración. La austeridad y el rigor, sobre todo financieros, que habían creado el clima de "confianza" tan caro a estos sectores, se esfumaba con una medida que mucho les recordaba la reforma agraria y las nacionalizaciones.

Además, la medida tenía un vicio que para el sentido común ha sido fuente de casi todos los males del país: la ineficiencia burocrática. La lista de los inmuebles incluidos en el decreto expropiatorio había sido hecha con tal precipitación, que en ella aparecían casas unifamiliares habitadas por sus propietarios, predios que ya eran propiedad del gobierno, vecindades que habían sido adquiridas por sus antiguos inquilinos y, sobre todo, vecindades que no habían sufrido daños.

Pero esta solidaridad con los "damnificados de la expropiación" no se expresó políticamente sino a través de las usuales medidas de emergencia en casos de "pérdida de confianza": la compra de dólares. Aunque esto es difícil de comprobar, para algunos economistas esta reacción contribuyó a la devaluación que sufrió el peso en las semanas siguientes.

Así, no es de extrañar que el gobierno capitalino haya dedicado un esfuerzo considerable a contrarrestar esa reacción: en los hechos, mediante la rectificación del decreto; en el discurso, mediante una amplia difusión de las razones justificativas de la expropiación, las cuales son sumamente reveladoras.

Los nuevos decretos publicados los días 21,22 y 23 de octubre, que redujeron el número de predios expropiados de 5448 a 4335 , constituyeron una primera rectificación de carácter general con base en un criterio dado a conocer por las autoridades: se excluían de la lista todos los predios ubicados en barrios "no populares". Así, los damnificados de las áreas que por lo general alojan población de clase media, tendrían que buscar opciones de reconstrucción distintas a las que se abrían con la expropiación. Adicionalmente, el gobierno capitalino, que reconoció que se habían cometido numerosos errores en la identificación de los predios, anunció su disponibilidad para tramitar la revocación en todos los casos de predios que "no debian haber sido incluidos", aunque nunca se hicieron públicos los criterios conforme a los cuales un predio debía o no ser expropiado.

Reconocer e incluso enmendar algunos errores no era, sin embargo, tan difícil como ofrecer una justificación por esa vuelta a las formas diríase 
"tradicionales" del sistema político mexicano, que habían sido desterradas del proyecto lamadridiano. Existía incluso un contraste entre el tono severo y justificatorio del discurso propiamente gubernamental y la manera como se festejó la medida en las organizaciones del partido oficial. Las razones ofrecidas a la opinión pública pueden resumirse en dos:

La primera de ellas, que no aparece mencionada en los decretos expropíatorios aunque sí en los informes de la Comisión Metropolitana de Emergencia, es el deterioro habitacional que se ha producido en el centro de la ciudad asociado a la permanencia de las "rentas congeladas". "Era un círculo vicioso que había que solucionar de la mejor manera posible. Por una parte al propietario no le interesaba realizar mejoras al inmueble. . Por otro lado, el inquilino no tenía ningún interés en invertir sus pequeños ahorros en mejorar la vivienda puesto que la misma no era de su propiedad" (CME, 1985: 12). El sismo traía consigo una buena oportunidad para intervenir en la cuestión. Lo que nunca se aclaró es por qué quedaron sin expropiar numerosas vecindades con rentas congeladas.

La segunda razón es, quizá, la más importante. Según palabras del propio regente de la ciudad, las protestas de los damnificados constituían una "amenaza a la paz social". La noción de "paz social" es sin duda difícil de precisar; sin embargo, es insostenible que la movilización social que comenzó a desarrollarse después del sismo por la vivienda haya rebasado los límites de la protesta pacífica. Lo que sí rebasaba eran los mecanismos tradicionales de control político del partido social. En cualquier caso, lo que interesa resaltar es el hecho de que una de las justificaciones de la expropiación, frente a las reacciones que arriba señalamos, no haya sido la necesidad de vivienda de la población afectada, sino el riesgo que representaba la organización independiente de esa población para el sistema político.

Pero mientras las palabras se disolvían en la simple indiferencia con que suele escucharse el discurso oficial, los hechos se hacían cada vez más complejos. Revisemos, en primer lugar, las estrategias de los propietarios frente a la expropación. A este respecto, vale la pena señalar que una gran parte de ellos no opuso recurso legal alguno en contra de la expropiación. Se presentaron 1280 solicitudes de revocación y 304 solicitudes de amparo, lo que significa que muchos propietarios confiaron en recibir una indemnización satisfactoria. Así, para fines de 1985 el propio DDF, había revocado la expropiación en $10 \%$ de los casos. Lo que aún faltaría por resolverse serían los juicios de amparo, a los cuales nos referiremos en la última sección de este trabajo.

Dejando de lado los aspectos jurídicos de la expropiación, conviene preguntarse si en realidad significó un daño económico a los propietarios. La pregunta surge, obviamente, en torno al monto y las condiciones de la indemnización. Aunque en el texto del decreto sólo se habló de un plazo hasta de diez años para el pago, cosa que provocó la desolación de los 
afectados, el gobierno de la ciudad se apresuró a señalar que se pagaría a valores actualizados a la fecha del decreto, ${ }^{6}$ en un intento más de obtener consenso en torno de la medida. El 3 de diciembre se publicó un acuerdo en el Diario Oficial en el que se anunciaba que las indemnizaciones se cubrirían mediante la emisión de "Bonos de la reconstrucción" (Bores), que serían negociables en la bolsa de valores y devengarían intereses a las tasas bancarias prevalecientes.

A mediados del mes de enero, el DDF depositó la suma de 25 mil millones de pesos en un banco para garantizar el pago de los Bores, y anunció el inicio de la emisión. Se invitó a los propietarios a presentar su documentación para recibir los bonos correspondientes, señalándose que los intereses comenzarían a contar a partir de la expropiación. Es muy difícil, aún hoy, saber si los bonos serán ventajosos al conjunto de los propietarios, debido sobre todo a la gran diversidad de situaciones en que se encontraba cada uno. En un extremo, los propietarios de vecindades y edificios con una alta proporción de viviendas en renta congelada que no sufrieron daños considerables, están recibiendo un beneficio inesperado, ya que sus expectativas de obtener altas rentas dependía de la generalmente remota posibilidad de desalojo total de los inquilinos. Ésta es la situación de gran parte de los "afectados" y hay que añadir que aún en los casos (menos extremosos) donde la mayoría de los inquilinos no tienen rentas congeladas, la tasa de ganancia es inferior al interés bancario que ahora perciben por sus Bores. En el otro extremo, están los propietarios de los edificios y vecindades que fueron totalmente derrumbados con el temblor y con ello quedaron "libres" de inquilinos. Aquí la expropiación acaba con la expectativa de obtener las ganancias tan largamente esperadas por el propietario cuyo obstáculo era el arrendamiento, aunque como era de esperarse después de los efectos devastadores que produjo el sismo en los edificios de oficinas precisamente del centro de la ciudad, la promoción inmobiliaria no ha acudido a la compra de lotes baldíos con la misma velocidad que antes. Independientemente de lo que signifique la indemnización para cada propietario (es decir, en relación con el valor comercial de los predios) es altamente significativo que el gobierno haya asumido, a través de los Bores, un importante compromiso hacia los propietarios cuando, a cuatro meses del terremoto, no había iniciado inversiones considerables err el prograrns de renovación habitacional.

Así, mientras la situación de los propietarios se aclaraba cada vez más, la de los "beneficiarios" seguía siendo tan incierta como el día de la expropiación. Consideremos ahora la perspectiva que se les presentaba en esos meses.

La población a quien va dirigido el Programa Emergente de Renova-

\footnotetext{
${ }^{6}$ Nunca se aclaró si se considerarían los daños ocasionados por el sismo como una causa de depreciación.
} 
ción Habitacional Popular del Distrito Federal, ${ }^{7}$ que es en principio la misma población que habitaba los inmuebles expropiados, está formada por aproximadamente $\mathbf{4 5}$ mil familias, cifra nada despreciable comparada con el total de acciones de vivienda que lleva a cabo el gobierno federal al año ${ }^{8}$ aunque es preciso hacer notar que no constituye la totalidad de la población damnificada por el sismo (sobre este punto, véase el artículo de Priscilla Connolly en este mismo volumen).

El efecto del decreto expropiatorio sobre los habitantes de los edificios y vecindades expropiados fue en cierto modo análogo al que produjo entre los propietarios: se uniformó la situación de un conjunto de agentes sociales cuyas situaciones eran enormemente diversas antes de la expropiación, lo que significa que los "beneficios" que recibirán serán iguales desde el punto de vista del Estado y diferenciados desde el de las familias individualmente consideradas.

Los habitantes de los inmuebles tienen independientemente de su estatus antes del sismo, un derecho de preferencia para adquirir las viviendas en el mismo lugar. Dejando de lado el costo de adquisición de la vivienda, al que nos referimos más adelante, ese derecho de preferencia es una ganancia para quienes ocupaban su vivienda en una situación irregular (contratos vencidos, subarriendos no autorizados, etc.), que representaba algún tipo de inseguridad legal en la tenencia, así como para quienes sufrieron la destrucción total de su vivienda, con lo cual su contrato de arrendamiento podía darse por terminado, cosa que sucede cada año en la temporada de lluvias al desplomarse los techos reblandecidos de las viejas vecindades.

En el otro extremo, está un amplio sector que, sin haber sufrido daños considerables en sus viviendas por efecto del sismo, gracias a la expropiación dejan de ser inquilinos y por tanto pierden el derecho al uso de las mismas. Antes pagaban una renta baja por una vivienda deteriorada (con un grado variable de inseguridad jurídica); ahora tendrán que comprar esa vivienda, sumandb el costo de su mejoramiento, para seguir viviendo en el centro de la ciudad. No parece haber alternativa.

Era aquí donde surgía la pregunta fundamental acerca del programa habitacional y la expropiación que le dio origen: ¿cuáles serían las condiciones financieras que se "ofrecerían" a las familias que habitaban los inmuebles expropiados? Durante casi seis meses esta pregunta permaneció sin una respuesta clara. Y dada la orientación de la política económica de la presente administración, muchos temieron que al no poder cubrir las condiciones financieras del programa tendrían que dejar sus

\footnotetext{
${ }^{7}$ Aprobado mediante decreto que se publicó el 14 de octubre en el Diario Oficial.

${ }^{8}$ Para 1985, se tenía programado realizar 157954 viviendas terminadas de un total de 362912 acciones de vivienda. (́Gobierno de Miguel de la Madrid, 1986).
} 
viviendas (¡aún cuando éstas no hubieran sido dañadas por el sismo!) para convertirse, ellos sí, en los damnificados de la expropiación.

Antes de referirnos a la forma en que se resolvió éste y otros interrogantes del PRHP, es importante señalar el significado político de la expropiación. Por un lado, la expropiación trajo consigo la recuperación de la "normalidad política"' que el sismo había alterado. Su efecto casi inmediato fue una reconstitución de los agentes involucrados y sus prácticas. El universo caótico y ampliamente movilizado de los damnificados se fue transformando en una ordenada fila frente a la ventanilla del subsidio oficial. Lo más revelador es quizá el hecho de que la expropiación haya sido una demanda popular (cuestión que fue cuidadosamente omitida del discurso oficial). Aunque enfrentadas al gobierno, las organizaciones de vecinos depositaban en él toda su confianza al solicitarle una expropiación cuyos efectos sociales no podrían predecir. Esto parece ser una indicación suficiente de que el paternalismo, como relación política, cuenta con una base real en el seno de la sociedad civil y gracias a ello está tan sano como en sus mejores años.

Visto desde la perspectiva del Estado, la "estrindente contradicción. . . (de la expropiación) con todas las declaraciones programáticas de este sexenio"' (Salazar, 1985) es también digna de señalarse: si nos concediéramos la licencia de hablar del Estado como si fuera un sujeto ${ }^{9}$ podríamos ver la expropiación como el acto fallido provocado por la situación crítica, en el que afloró la verdadera naturaleza de un Leviatán que se había modernizado sólo en el nivel de la conciencia y que no había sido capaz de inventar nuevas formas de legitimación.

\section{La concertación y los compromisos}

Casi 6 meses después del sismo, la indefinición gubernamental en torno al PRHP había hecho disolver el efecto (esperanzador y desmovilizador) del decreto expropiatorio. Los conflictos interinstitucionales deterioraban las relaciones del gobierno con las organizaciones de damnificados y retrasaban la definición de las condiciones financieras, jurídicas y técnicas del programa.

Por fin, el 13 de mayo, se produjo un importante cambio de rumbo con la firma del "Convenio de concertación democrática para la reconstrucción de vivienda del Programa de Renovación Habitacional Popular'. Se trata de una de las facetas del proyecto lamadridiano hasta entonces poco observadas en las relaciones con los damnificados. La "concertación democrática", que es la forma específica que asume el contractualismo

${ }^{9}$ Cosa demasiado frecuente en círculos académicos, donde el Estado es "alguien" capaz de saber, pensar, decir y, sobre todo, conspirar. 
político ${ }^{10}$ en la presente administración federal, supone el establecimiento de compromisos entre el gobierno y organizaciones sociales en torno a problemas concretos.

La firma de este convenio parecería, entonces, la recuperación del "estilo personal" que se había perdido con la expropiación. Sin embargo es preciso señalar que esta última y el convenio no son excluyentes sino complementarios. La expropiación había resuelto - con las inconveniencias que señalamos en otras partes de este trabajo- el problema crucial de definir el alcance territorial del programa de PRHP cosa a la que difícilmente se habría llegado a través de medios de concertación.

Ahora bien, cabe preguntarse sobre el valor jurídico de este convenio. A pesar de estar prevista en la Constitución esta vertiente de la gestión pública, y de que el documento toma la forma del acto jurídico por excelencia - el contrato- no puede decirse que surta efectos propiamente jurídicos. No existe en el sistema jurídico mexicano procedimiento legal alguno por el que una de las partes pudiese exigir el cumplimiento de las obligaciones de su contraparte. Se trata más bien de un conjunto de compromisos de carácter polítiço y es ahí donde reside su significado. Por un lado, el gobierno federal define con precisión los alcances del compromiso que había asumido en forma indefinida con la expropiación. Por el otro, un conjunto de organizaciones sociales manifiestan su conformidad con esos alcances.

Si bien es cierto que algunas de las cláusulas parecen haber sido incluidas a propuesta de las organizaciones ${ }^{11}$ es difícil suponer que el contenido general del convenio haya sido resultado directo de un proceso de negociación entre las partes que lo suscribieron. El alto nivel de subsidio oficial, que es el más notorio elemento del PRHP, sería en todo caso atribuible al peso de la movilización social durante todos esos meses y no a una negociación contractual, cuyo mérito fundamental es, en todo caso, el reconocimiento de fuerzas políticas distintas a las del partido oficial.

En lo que se refiere a la identidad misma de las partes, no puede dejar de señalarse una gran ambigüedad. Por el gobierno de la República la identidad es clara, firman el jefe del DDF, el secretario de Desarrollo Urbano y Ecología y el director general del PRHP, o sea los principales órganos responsables técnica y políticamente, del programa; por "la sociedad" firman los representantes de una multitud de entidades y organizaciones cuya pluralidad va más allá de lo imaginable. Sorprende encontrar, por ejemplo, entidades del propio gobierno federal (como el INAH) engrosando las filas de "la sociedad", además de una serie de organizaciones que no exis-

10 Para un análisis del contractualismo político, véase Bobbio (1986).

11 De acuerdo con Leslie Serna, dirigente de la Unión de Vecinos Nueva Tenochtitlán, la cláusula relativa a la conservación de los monumentos fue incorporada al convenio a propuesta de esa organización. 
ten más allá de sus membretes. Puede decirse, entonces, que no son todos los que están. Sería poco afortunado, por otro lado, decir que tampoco están todos los que son, es decir, que las verdaderas fuerzas políticas que en un grado variable están presentes en las diversas organizaciones, permanecen ocultas. ${ }^{12}$ Parece más saludable para estas organizaciones no identificarse con las corrientes políticas que corren en su interior, pues ello podría tener el efecto nocivo de consolidar o incrementar la influencia de los partidos políticos como tales dentro de las organizaciones.

En lo que se refiere al contenido del Convenio, se destacan tres elementos fundamentales. El primero es la definición del precio y las condiciones de pago de cada uno de los tres tipos de acciones de vivienda que se llevan a cabo. La cláusula segunda dispone al respecto

el precio de venta de cada vivienda nueva por dos millones ochocientos noventa y seis mil pesos, que incluye la adquisición del terreno; la forma de pago, que se realizará mediante abonos mensuales equivalentes a $30 \%$ del salario mínimo mensual en el Distrito Federal; el interés anual sobre saldos insolutos de $17 \%$, sin enganche ni anualidades, con un plazo de ocho años y medio; la posibilidad de realizar pagos adicionales para disminuir el saldo del adeudo y la obligación de iniciar el pago en abonos mensuales al mes siguiente de haber recibido la vivienda definitiva terminada.

Cuando se trate de reparaciones menores y de rehabilitación de vivienda, los contratos especificarán el precio de la obra en cada caso, que no rebasará la cantidad de un millón ciento sesenta mil pesos, para reparaciones menores, y de dos millones doscientos veinticinco mil setecientos pesos para la rehabilitación. La forma de pago, en estos casos, será: $20 \%$ del salario mínimo mensual, con un interés de $13 \%$ para reparaciones menores, con un plazo de cinco años y medio; y para la rehabilitación de vivienda, mensualidades equivalentes a $25 \%$ del salario mínimo y un interés del $16 \%$, con un plazo de ocho años. Estos contratos incluirán la traslación de dominio (cláusula segunda).

En segundo lugar, se definen tres opciones de vivienda en tanto se llevan a cabo las obras del programa, que pueden tener carácter de vivienda temporal o definitiva:

A) La ayuda de renta mensual de 30 mil pesos por el plazo necesario, con pago anticipado de tres meses y la cobertura de gastos de mudanza por 50 mil pesos para cada movimiento de salida y retorno, opción diseñada para quienes pudiendo ser alojados en casa de familiares, amistades o de familias solidarias, resuelvan así el problema de habi-

12 Es bien sabido, por citar sólo dos ejemplos, que el PR predomina en la Federación de Comités de Reconstrucción, igual que el PST en el Directorio de Damnificados. 
tación temporal mientras termina la construcción de su vivienda definitiva (el apoyo mensual de 30 mil pesos equivalente al doble de la cantidad que se pagará al adquirir las viviendas terminadas). De esa manera se reducirán los problemas, se aprovechará mejor la infraestructura disponible en la ciudad y se apoyará la economía de otras familias.

B) Las familias que aportan al Infonavit, y así lo deseen, tendrán a su disposición 1500 viviendas ya construidas en la zona metropolitana.

C) Las familias que no sean aportantes al Infonavit, y así lo deseen, tendrán acceso a las viviendas definitivas que forman parte de la bolsa de vivienda de la zona metropolitana de la ciudad de México o de promociones en el interior del país que impulsen la descentralización.

D) Para quienes no estén en disposición de aprovechar las anteriores, se ofrecerá con nuevos criterios constructivos y seguridad reforzada, vivienda temporal.

La opción de vivienda provisional que los damnificados elijan será definida y pactada en la misma sesión de la firma de los contratos de compraventa (cláusula tercera).

Finalmente, el gobierno federal se compromete a entregar las viviendas en plena propiedad, al obligarse a firmar "un sólo contrato de compraventa y obtención de crédito, donde se establece: la venta libre de gravamen y responsabilidad a los beneficiarios, quedando el PRHP obligado a "constituir en el inmueble el régimen de propiedad en condominio" (cláusula segunda). Sin negar la importancia de los aspectos políticos y económicos de este convenio, sobre lo cual pueden consultarse los trabajos de E. Duhau y P. Connolly en este mismo volumen, concentraremos nuestra atención en el régimen de propiedad al que quedarán sujetas las viviendas del PRHP.

\section{La definición burocrática de la propiedad}

El PRHP es el primer programa de vivienda del gobierno mexicano en el que un alto grado de subsidio no viene acompañado de algún tipo de restricción jurídica a la libre disposición del inmueble por parte del beneficiario. Desde las primeras intervenciones estatales masivas en la formación de colonias populares, durante el sexenio de Ávila Camacho, en las que los lotes se entregaban bajo el régimen de patrimonio de familia, política que estaba incluso consagrada en reglamentos y decretos, ${ }^{13}$ se ha tra-

${ }^{13}$ El artículo 16 del Reglamento de asociación pro-mejoramiento de las colonias del Distrito Federal (Diario Oficial, 28 de marzo de 1941) disponía: "al adquirir un lote o terreno que pertenezca al Departamento del Distrito Federal, todo colono se obliga a constituir con él, el patrimonio de su familia, con arreglo al. . . Código Civil; y sin la aceptación de este requisito, no podrá ser enajenado el lote o terreno". 
tado de evitar, de modo explícito, que "se especule" con terrenos o casas por los que los destinatarios no han pagado el valor comercial.

Paradójicamente, siendo ésta la primera vez que se produce un cambio de rumbo en este sentido, es justamente cuando el gobierno ha enfrentado una seria oposición a su iniciativa. De hecho puede decirse que, dentro de la agenda de la reconstrucción el tema del régimen de propiedad de las viviendas es uno de los que más ha dividido al gobierno y la oposición, incluida una parte importante de las organizaciones de damnificados, las cuales insistieron sin éxito en la necesidad de una forma de propiedad que impidiera la libre circulación de la vivienda. A nuestro modo de ver, esta diferencia se explica por los marcos de referencia en que se colocan los actores. Por un lado, los dirigentes de las organizaciones, sobre todo cuando están vinculados a los círculos universitarios, tienden a ver en la propiedad privada (y su garante, el Estado) la fuente de todos los males de la ciudad. Ante la evidente posibilidad de que una parte de la población beneficiada por el programa sea desplazada por sectores de más altos ingresos a través de los mecanismos del mercado, suelen aceptar como viable cualquier figura jurídica que restrinja la libre disposición de la vivienda, más aún si se asemeja a una fórmula de tipo colectivo. Como se verá más adelante, ésta no ha pasado de ser una postura meramente ideológica, que ni está apoyada en un conocimiento de los verdaderos procesos de apropiación del suelo ni se traduce en una propuesta articulada jurídicamente.

Por su parte, los funcionarios públicos, si bien no necesariamente se oponen a formas jurídicas distintas a la plena propiedad privada, han estado insertos en un marco de referencia que conduce a posponer toda discusión a este reșpecto. Ese marco consiste no únicamente en la actual tendencia hacia la reprivatización que se observa en la política económica. De un modo más inmediato, la experiencia reciente, antes y después del sismo, de los certificados de participación inmobiliaria en el conjunto Nonoalco-Tlatelolco, parece aconsejar al gobierno restringir al máximo su injerencia en la propiedad y administración de la vivienda promovida por sus organismos. ${ }^{14} \mathrm{Si}$ a esto se añade la urgencia — justificada o no- de

Consecuentemente, las expropiaciones de terrenos para crear o regularizar colonias en esa época (ver nota 4 supra) establecían de modo expreso este requisito.

${ }^{14}$ Desde varios años anteriores al sismo, el Fonhapo había tratado, sin éxito, de constituir el régimen de condominio en los edificios del conjunto que ya habían sido totalmente pagados, tal como estaba originalmente previsto. Sin embargo su gestión se enfrentó con la resistencia de los tenedores de certificados de participación inmobiliaria a convertirse en propietarios, pues ello les permitía seguir disfrutando de un subsidio oficial para el mantenimiento de sus edificios, mientras que podían disponer libremente de sus departamentos mediante la venta de los certificados, cosa que inicialmente estaba prohibida. Esta situación dio como resultado que, con el sismo, el gobierno haya tenido que asumir la responsabilidad íntegra de la reconstrucción del conjunto. 
desaparecer el organismo RHP una vez concluidas las obras, se entiende que la elección de la plena propiedad haya llegado al extremo de renunciar al establecimiento de hipotecas para garantizar el pago de los créditos. En otras palabras, se corre el riesgo de lograr una baja recuperación del financiamiento, con tal de entregar, con la plena propiedad, toda la responsabilidad legal de las viviendas a sus nuevos propietarios.

En forma paralela a la toma de esta decisión dentro del poder ejecutivo, el poder legislativo generaba una adición a la ley de condominios que apuntaba en la misma dirección.

El 26 de diciembre de 1985 se leyó en la Cámara de diputados una iniciativa presentada por diputados del PRI, PDM, PPS, PARM y PST, la cual se turnó a la comisión del Distrito Federal para su estudio y dictamen. Y no fue sino hasta el 16 de abril de 1986, durante un periodo extraordinario, cuando se presentó y discutió el dictamen de la comisión. A pesar de la pobreza de la propuesta y de la esterilidad de los debates, es interesante recoger algunos de sus aspectos.

$\mathrm{Al}$ encontrar que el dictamen de la mayoría priista no contemplaba restricción alguna a la propiedad de las viviendas, dos de los partidos que originalmente habían suscrito la iniciativa, el PPS y el PST, retiraron su apoyo al nuevo proyecto y coincidieron en proponer la figura del patrimonio familiar. Sin embargo, no formularon un proyecto legislativo alternativo al del PRI.

Lo mismo ocurrió con el resto de los partidos de izquierda representados en la cámara de diputados. Todos manifestaron su oposición a la privatización de la vivienda del PRHP pero ninguno formuló un proyecto consistente, por lo que no lograron pasar de una discusión meramente ideológica. Por ejemplo, cuando el diputado Manuel Terrazas, del PSUM, dijo: "Lo que nosotros propusimos es que se buscara una figura que resolviera el problema de la seguridad de la tenencia de la vivienda. . .", ${ }^{15}$ hacía evidente que no contaban con una propuesta precisa. Por su parte, el diputado Efraín J. Calvo Zarco, del PRT, reconocía que (los miembros de esa fracción parlamentaria) “. . . elaboramos una propuesta de régimen de propiedad retomando una idea que planteó por ahí el director de Renovación Habitacional Popular, a la que dimos forma. . ."

La propuesta de ese partido consistía en hacer a los vecinos copropietarios de la vecindad en su conjunto; la restricción más importante señalaba que "los vecinos sólo podrán ceder sus derechos bajo cualquier título gratuito $u$ oneroso a la asamblea de vecinos o a terceros siempre y cuando éstos se autoricen por dos terceras partes de la asamblea". No entraremos al análisis detallado de esta propuesta; baste con señalar que ella traía consigo una serie de implicaciones que se ignoraba por completo, como la

${ }^{15}$ Las citas de las intervenciones de los diputados fueron tomadas de la versión del departamento de taquigrafía de la cámara de diputados, turnos 62 a 151. 
necesidad de dotar a la "asamblea de vecinos" de personalidad jurídica para adquirir derechos, y de adaptar al régimen de la copropiedad una gran cantidad de mecanismos que le son totalmente ajenos.

En síntesis, lo que queremos destacar es que los partidos de izquierda carecieron de una visión suficientemente clara del problema para presentar una propuesta coherente con sus plataformas ideológicas. En lo que se refiere a los partidos de derecha, no es de extrañar, por un lado, que el PDM haya votado en favor del dictamen de la fracción priísta, ya que éste era perfectamente consistente con el lema pedemista de "todos propietarios". El PAN, que tampoco presentó una visión clara del problema, únicamente propuso que se retiraran del dictamen las amplias facultades discrecionales que se estaban otorgando al DDF. Conviene hacer notar que en este punto coincidieron el PAN y todos los partidos de izquierda.

Como era de esperarse, ninguna de las propuestas de la oposición, aún las que señalaban simples pero evidentes fallas de redacción, fueron atendidas por la mayoría priista, que aprobó el proyecto sin una sola modificación.

En el senado, el proyecto tampoco sufrió modificaciones, aunque vale la pena señalar que en el dictamen correspondiente de esa cámara se incluye la insólita afirmación de que se trata de "una nueva forma de propiedad social", cuando la realidad es totalmente distinta.

A estas alturas, conviene tratar de definir en qué consiste el supuesto nuevo régimen "de propiedad en condominio de carácter vecinal", contenido en el capítulo VIII de la Ley de Condominios (Diario Oficial, 9 de mayo de 1986). La interpretación textual del artículo 46 de la ley nos hace pensar que, en rigor, no se trata de un nuevo régimen, sino de la posibilidad de crear un régimen condominal distinto en cada caso. El mencionado artículo dice:

El régimen de propiedad en condominio de carácter vecinal es un régimen excepcional que se regirá por las disposiciones de esta Ley, las que contenga la declaratoria de las autoridades competentes que lo autoricen, las de las escrituras en que hubiere establecido dicho régimen y las demás disposiciones jurídicas aplicables, en lo que no se oponga a lo establecido en el presente capítulo.

Así, por una parte, el texto legal anuncia que se trata de un "régimen excepcional" lo cual significa que no podría estar formado por las mismas reglas generales del condominio, pues sería absurdo pensar que se adicione la ley para crear un nuevo régimen que es igual al existente. Sin embargo, por otra parte, el artículo transcrito no define las características del nuevo régimen, sino que deja que sean dos instancias futuras las que lo determinen: la declaratoria "de las autoridades competentes que lo autoricen" y "las escrituras en que se hubiere establecido dicho régimen". En otras palabras, no es sólo en la ley sino también en actos posteriores, 
donde se definirán las características del nuevo régimen. Así, la ley está autorizando a quienes expiden "la declaratoria" y "las escrituras" a fijar las disposiciones que regirán el condominio vecinal. De ser así, estaríamos frente a una situación sin precedentes en el derecho civil, en la que pueden aparecer distintas formas de propiedad en cada caso.

Lo primero que hay que determinar es ¿quién decide el contenido de "las escrituras"? Éstas no son sino los documentos en que se hace constar la celebración de un acto jurídico. En el caso del PRHP, ¿quién es el "autor" de esas escrituras?, ¿el organismo PRHP?, ¿un notario?, ¿los vecinos? Esta indeterminación cuestiona toda posibilidad de estos últimos de participar en la definición del régimen de propiedad, aunque una interpretación benevolente - combinada con una actitud abierta y paciente por parte del notario- podrían abrir esa posibilidad.

En lo que no hay lugar a dudas es en la intervención del DDF en la definición de las reglas del condominio vecinal. Aparentemente no hay novedad alguna en esta facultad administrativa, ya que la constitución del régimen de condominio está sujeta a dicha autorización (mal llamada "declaratoria" por la ley) desde 1972, cuando fue expedida la ley a que nos referimos. Sin embargo, es preciso señalar que la declaratoria del DDF que establecía la ley en su versión original, tiene que ver con el cumplimiento de disposiciones de carácter urbanístico y no con el régimen de la propiedad misma. De acuerdo con los principios del derecho civil aplicables a esta materia, el régimen de condominio se constituye por voluntad de las partes y no como resultado de un acto administrativo. Este último está relacionado, insistimos, con el control de la urbanización y no de la transmisión o modificación de régimen de la propiedad. En cambio, en el condominio vecinal, la declaratoria o declaración (el texto legal no es consistente en la terminología a este respecto) del DDF adquiere la función de autorizar (o no) el tipo de propiedad a la que quedará sujeto el inmueble, ya que en el artículo transcrito se dispone claramente que esa declaratoria podrá contener disposiciones relativas al régimen de condominio vecinal. Lo grave del asunto no es sólo que la autoridad tenga facultades para autorizar -o desautorizar- la constitución del condominio vecinal, sino el hecho de que la ley no señala límite alguno para el ejercicio de esa facultad. Es decir, el DDF gozará de una amplia discrecionalidad en cuanto al tipo de condominios vecinales que podrá autorizar o negar. Todo ello convierte a la constitución del condominio vecinal, en el mejor de los casos, en un acto de concertación en donde la buena voluntad ha de suplir a la ley.

Conviene señalar que la discrecionalidad que se otorga al DDF no se reduce a las reglas relativas a la propiedad de los inmuebles, sino que abarca aspectos arquitectónicos y administrativos, aun cuando no se precisa el alcance de los mismos. Así, se dispone que la declaratoria a través de la cual el DDF apruebe la constitución del condominio vecinal "seña- 
lará las características del proyecto que apruebe y los requisitos administrativos a que dicho proyecto deberá estar sujeto" (artículo 48). Como es bien sabido, en virtud del principio de legalidad consagrado en la constitución, los requisitos administrativos de los actos de los gobernados deben ser establecidos por la ley o, en derivación de ésta, por un reglamento administrativo, de modo tal que dichos requisitos no sean fijados con el exclusivo arbitrio de las dependencias del poder ejecutivo, cuya función es vigilar el cumplimiento de tales requisitos mas no crearlos.

Pero quizá el aspecto en el que se va más lejos en cuanto a dotar a la autoridad administrativa de nuevas atribuciones no reglamentadas, es el que se refiere a las formas de organización de los grupos para la administración de los inmuebles. Al respecto, el artículo 50 dispone lo siguiente:

Para la administración y vigilancia de ésta (sic), en los inmuebles sujetos al régimen de propiedad en condominio de carácter vecinal, la declaratoria a que se refiere el artículo $3^{\circ}$. de esta Ley, dará preferencia a la forma de organización propuesta por los beneficiarios de cada proyecto.

En este precepto parece estar implícita la facultad del DDF de aprobar la forma de organización de los vecinos para la administración de sus inmuebles, ya que los beneficiarios tan sólo proponen una forma de organización. Es importante recordar que la constitución otorga la garantía de libre asociación (artículo noveno) por lo que ni una ley secundaria ni mucho menos la autoridad administrativa pueden restringir dicha libertad. En consecuencia, los grupos de beneficiarios podrán adoptar la forma organizativa que consideren más conveniente, siempre que esta tenga un objeto lícito, en lo que se refiere a la administración del inmueble del que serán propietarios bajo el régimen de condominio vecinal. Cualquier restricción que el DDF impusiese a los vecinos en lo que se refiere a sus formas de organización en aplicación de esta ley, sería por tanto inconstitucional.

Todo lo anterior es resultado de una interpretación textual con la cual estamos haciendo pasar "un elefante por una rendija". Pero también se apoya en el supuesto de que hay una nueva forma de propiedad. Por lo que hemos dicho, si en algo se distinguiera esta nueva fórmula del condominio tradicional, sería no en su carácter "social", como pretende el dictamen del senado, sino en el peso que la ley otorga a la burocracia capitalina en la definición de las reglas del condominio vecinal.

Suponiendo que en realidad no se trata de un régimen de propiedad condominal "excepcional", la adición a la ley a primera vista se justifica porque establece un tratamiento preferencial en materia fiscal y constructiva. Pero un análisis cercano de la cuestión nos revela que ni siquiera eso quedó de la idea original que habían apoyado algunos partidos distintos al oficial. En primer lugar, la exención de "toda clase impuestos, derechos o contribuciones" que el texto de la iniciativa otorgaba para los "actos 
y contratos que se celebren para la constitución del . . . condominio de carácter vecinal" (artículo 51) fue trasladada al texto de la Ley de Hacienda y ahí sólo aparece referida a "las personas que como consecuencia de los sismos acaecidos el mes de septiembre de 1985 hubiesen perdido su vivienda". Es decir, estos beneficios fiscales no podrán ser disfrutados en el futuro por quienes adquieran viviendas en condominio vecinal.

En segundo lugar, se argumentó en favor del nuevo capítulo a la ley que

. . . si dejamos la aplicación de la Ley de Condominios tal y como está, tendrían nuestros compatriotas que tener cajones de estacionamiento, tendrían que tener en sus casas instalaciones hidráulicas sanitarias separadas. . " (diputado Lulio Valenzuela).

Este argumento ignora que las disposiciones sobre cajones de estacionamiento y otros aspectos del diseño y construcción de las edificaciones no están contenidas en la Ley de Condominios porque no forman parte del régimen de la propiedad sino de la producción de un edificio. De modo que un tratamiento especial en estas materias es objeto de ordenamientos, como el Reglamento de Construcciones y el de Zonificación, que nada tienen que ver con la forma de propiedad.

En suma, la pobreza del nuevo capítulo de la Ley de Condominios es una muestra de que el poder legislativo fue más un espacio del debate ideológico que una instancia generadora de normas jurídicas. El verdadero impacto de lo jurídico se está dando en un contexto totalmente distinto, el de la decisión judicial que define la validez de la expropiación.

\section{La definición judicial de la propiedad}

A medida en que los aspectos financieros y políticos del programa tendían a esclarecerse, uno de sus aspectos jurídicos adquiría cada vez mayor importancia. Los juicios de amparo, que al principio eran sólo 308, comenzaron a aumentar conforme el DDF notificaba a los propietarios la negativa de otorgar la revocación administrativa. En estos momentos (noviembre de 1986) no se dispone de información oficial sobre el número de predios en los que se ha otorgado el amparo en favor de los propietarios. Si bien se sabe que hay aproximadamente 450 juicios, esta cifra no da una idea precisa del impacto de los amparos sobre el programa, ya que, por una parte, el hecho de que exista un juicio de amparo no significa necesariamente que se vaya a resolver en favor del propietario. ${ }^{16}$ Por otro lado,

${ }^{16}$ En muchos casos, los propietarios han tenido dificultades para acreditar sus derechos sobre los predios o incluso para hacer comparecer en juicio a todos los copropietarios cuando el predio pertenecía a más de una persona. Esto ha signifi- 
un mismo juicio puede incluir varios predios. Más aún, es de suponer que los propietarios que tenían varias vecindades sean quienes con mayor interés - y recursos- defiendan su propiedad.

A pesar de la falta de información precisa, puede decirse que los amparos constituyen, hoy, la amenaza más importante para el cumplimiento de las metas del PRHP, ya que cada predio que se pierde se traduce en la necesidad de reubicar a quienes ahí habitaban hacia otros predios, con el consecuente aumento de la densidad. La única opción que se abre es la compra del predio a su propietario, en condiciones sumamente desventajosas para el PRHP, sobre todo cuando las obras están avanzadas.

Lo único evidente por ahora es que el marco jurídico de la propiedad representa un importante límite de la acción habitacional del gobierno. La pregunta que se abre es si estas limitaciones se derivan de algún elemento estructural del régimen de la propiedad, o si más bien son el resultado de la forma en que se elaboró el decreto expropiatorio en este caso. No nos referimos aquí a los errores que se cometieron en la integración de la lista de predios, que efectivamente contribuyeron al desprestigio de la medida, sino a la formulación legal del propio decreto.

De acuerdo con informaciones vertidas por algunos abogados litigantes, una de las causas que con mayor frecuencia se han señalado en las sentencias de amparo favorables a los propietarios, es el hecho de que no se integraron los expedientes con los estudios técnicos que demostraran la idoneidad de cada predio expropiado para satisfacer la causa de utilidad pública invocada, tal como lo ordena el artículo $3^{\circ}$ de la Ley de Expropiación. Debe reconocerse que era sumamente difícil realizar un dictamen para cada predio cuando, por un lado, no se había definido el criterio que debía guiar la selección, ${ }^{17}$ mientras que por otra parte era en muchos casos imposible saber hasta qué punto el estado ruinoso de un inmueble era atribuible al sismo o al proceso de deterioro tan generalizado en el área central.

Lo cierto es que se actuó con la premura de una situación de emergencia, sin contar con el marco jurídico existente para ese tipo de situación, es decir, la suspensión de garantías individuales. La decisión presıdencial de no acudir a esta última medida, colocó al gobierno en la difícil posición de actuar dentro de los límites de un estado de "normalidad" cuando en realidad se vivía una emergencia.

Si una vez resuelta la totalidad de los juicios de amparo se demuestra que un factor importante para su otorgamiento es la falta de expedientes técnicos previos al acto expropiatorio, podrá deducirse que no se trata

cado que numerosos juicios sean sobreseidos antes de entrar en la materia misma del conflicto.

${ }^{17}$ El decreto expropiatorio no precisaba la intención de abarcar exclusivamente inmuebles que habian sufrido daños por efecto del sismo. 
de una restricción estructural del régimen de la propiedad en México que impida el uso masivo de la expropiación para programas habitacionales. Más bien se trataría de una restricción coyuntural, es decir, derivada de las condiciones en las que se decretó esta expropiación.

Sin embargo, se han esgrimido otras razones que podrían resultar en el otorgamiento de algunos amparos. La más importante de ellas es el cuestionamiento que han hecho muchos propietarios a esta expropiación que priva a unos del derecho de propiedad para otorgar el mismo derecho a otros. Desde una posición muy distinta, los propietarios terminan por sostener la misma posición de los partidos de izquierda en la cámara de diputados: no se satisface una causa de utilidad pública otorgando las viviendas en propiedad privada. En suma, de ser esto así, la tendencia a convertir inquilinos en propietarios que aparece clara en el PRHP, estaría cuestionada por sectores sociales antagónicos. Si bien unos la impugnan por sus medios (la expropiación) y otros por sus fines (la propiedad), en este punto el argumento es el mismo. Sirva esto al menos para ilustrar la ambivalencia de las categorías jurídicas.

\section{Bibliografía}

Bobbio, N. (1986), El futuro de la democracia, México, FCE.

CEPAL (1985), Daños causados por el movimiento telúrico en México y sus repercusiones sobre la economía del país, 15 de octubre de 1985.

CME (Comisión Metropolitana de Emergencia) (1985), Informe (19 de septiembre al 19 de octubre de 1985).

CNR (Comisión Nacional de Reconstrucción) (1985), México está de pie. Instalación de la Coordinación de Vivienda, octubre de 1985.

DDF (1946), Memoria del Departamento del Distrito Federal 1940-1946, México, DDF.

Gobierno de Miguel de la Madrid (1986), Las razones y las obras. Crónica del sexenio 1982-1988. Tercer Año. México, FCE.

Lojkine, J. (1979), El marxismo, el Estado y la cuestión urbana, México, Siglo XXI.

RHP (Renovación Habitacional Popular) (1985), Informe del área jurídica del organismo Renovación Habitacional Popular, diciembre de 1985, (mimeo).

Salazar, Luis (1985), "Sismo, política y gobierno", en El Cotidiano (UAM-Azcapotzalco), año 2 , núm. 8, noviembre-diciembre, 1985. 
